\title{
Does ketamine provide a shorter time to sedation when compared to haloperidol and midazolam in the agitated ED patient?
}

\author{
Jessica Kent ${ }^{1}$ D $\cdot$ Emily Austin ${ }^{1,2,3} \cdot$ Brodie Nolan $^{1,2,4}$
}

Received: 18 October 2021 / Accepted: 6 December 2021 / Published online: 31 December 2021

(c) The Author(s), under exclusive licence to Canadian Association of Emergency Physicians (CAEP)/ Association Canadienne de Médecine d'Urgence (ACMU) 2021

Full Citation: Barbic D, Andolfatto G, Grunau B, Scheuermeyer F, Macewan B, Qian H, Wong H, Barbic S, Honer W. Rapid Agitation Control with Ketamine in the Emergency Department: A Blinded, Randomized Controlled Trial. Ann. Emerg. Med.. 2021

Abstract Link: https://www.annemergmed.com/article/ S0196-0644(21)00433-9/fulltext

Article Type: Randomized Control Trial

Ratings: Methods-4/5, Usefulness-4/5

\section{Introduction}

\section{Background}

Severely agitated emergency department (ED) patients require rapid stabilization to avoid endangering themselves and staff. Administration of intramuscular agents with rapid onset is preferred to maximize safety.

Jessica Kent

jekent@nosm.ca

1 Division of Emergency Medicine, Department of Medicine, University of Toronto, Toronto, ON, Canada

2 Department of Emergency Medicine, St. Michael's Hospital, Toronto, ON, Canada

3 Ontario Poison Centre, Toronto, ON, Canada

4 Li Ka Shing Knowledge Institute, St. Michael's Hospital, Toronto, ON, Canada

\section{Objective}

To compare time to sedation between intramuscular ketamine or a combination of intramuscular haloperidol and midazolam in ED patients with agitation.

\section{Structured methods}

\section{Design}

A single-center randomized controlled trial (RCT).

\section{Setting}

St. Paul's Hospital, an urban Canadian emergency department.

\section{Subjects}

Patients aged 19-60 years of age with severe psychomotor agitation measured by a Richmond Agitation Score (RASS) of 3 or greater.

\section{Intervention}

Ketamine $5 \mathrm{mg} / \mathrm{kg}$ intramuscular.

\section{Comparison}

Haloperidol $5 \mathrm{mg}$ and Midazolam $5 \mathrm{mg}$ intramuscular.

\section{Outcomes}

The primary outcome of this study was time from medication administration (in minutes) to adequate sedation, defined as Richmond Agitation Score (RASS) of -1 or less. Secondary outcomes of this study included the need 
for rescue medication and the occurrence of prespecified adverse events.

\section{Main results}

Of 308 patients screened, 80 were enrolled and randomized equally into the two study arms. The majority of patients enrolled were male (68\%), with a median age of 35 years [IQR 29.0-41.5]. A greater proportion of patients receiving ketamine were male $(85 \%)$ with a higher RASS score of $4+(64.1 \%)$. The primary outcome of median time to sedation was $14.7 \mathrm{~min}$ for midazolam and haloperidol versus $5.8 \mathrm{~min}$ for ketamine (difference $8.8 \mathrm{~min}$ [95\% confidence interval (CI) 3.0 to 14.5]). Adjusted Cox proportional model analysis favored the ketamine arm (hazard ratio $2.43,95 \% \mathrm{CI}$ 1.43 to 4.12$)$. As a secondary outcome, 5 (12.5\%) patients who received ketamine and $2(5.0 \%)$ patients who received midazolam and haloperidol experienced serious adverse events (difference $7.5 \%$ [95\% CI - 4.8 to 19.8\%]). There was no difference in proportion of patients requiring rescue medications between groups. The trial was halted early due to COVID-19 restrictions.

\section{Appraisal}

\section{Strengths}

- Prospective RCT adherent to CONSORT guidelines

- Well-defined clinical question with practical design

- Clear inclusion and exclusion criteria which did not exclude those with schizophrenia/psychosis

- Treatment allocation concealed from staff, investigators, research assistants and patients

- Use of RASS as an objective measure for both inclusion into the study and target for sedation

- Practical comparison using appropriate dosages of haloperidol and midazolam

- Use of standardized criteria for prespecified adverse events

\section{Limitations}

- Small sample size which did not reach target

- Single-centre trial at a hospital where staff were comfortable managing severely agitated patients which may not reflect all EDs

- Possible recruitment bias—study hours between 8 am and midnight

- Potential for un-blinding-ketamine split into multiple vials based on patient weight, whereas midazolam and haloperidol given in a single vial
- Frequency of harms commonly encountered when treating agitated patients not reported (ex, needle stick injury)

- Impact on disposition/length of stay not reported

\section{Context}

Benzodiazepines, antipsychotics, or a combination of both have typically been recommended for chemical sedation of agitated ED patients [1]. While effective, these medications are slow to work and have unwanted side effects including respiratory depression [1]. Given ketamine's rapid onset and favorable side effect profile, the American College of Emergency Physicians has recommended its use for the rapid sedation of severely agitated patients whilst recognizing the need for further high-quality studies to establish safety/efficacy [2, 3]. Local experts in Toronto suggest using intramuscular ketamine in very agitated patients who are at imminent risk of harm to themselves or staff and require rapid sedation to facilitate a safe and thorough assessment.

\section{Bottom line}

In this single-centre randomized control trial, ketamine provided a significantly shorter time to sedation in comparison to haloperidol and midazolam without compromising safety in the severely agitated ED patient. These results need to be taken in the context of a study that did not reach target sample size and were under-powered to detect adverse events. Despite the limitations, ketamine appears to be a viable option for initial stabilization of the severely agitated ED patient if administered in a highly monitored setting.

\section{Declarations}

Conflict of interest We have no conflicts of interest to declare and received no funding for this study.

\section{References}

1. Korczak V, Kirby A, Gunja N. Chemical agents for the sedation of agitated patients in the ED: a systematic review. Am J Emerg Med. 2016;34(12):2426-31.

2. Coffey S, Vakkalanka P, Wallace K, et al. Out-of-hospital use of ketamine for agitating and subsequent emergency department intubation: a retrospective study. Ann Emerg Med. 2020;76(4):S158.

3. Nazarian D, BroderJ, Thiessen M, et al. Clinical policy: critical issues in the diagnosis and management of the adult psychiatric patient in the emergency department. Retrieved on 5 Oct 2021. https://www.acep.org/contentassets/04e7623d4991457bbcd 9 a53a40ba427d/cp-adultpsychiatricpatient-1.pdf 